\title{
POSITRONIUM DEUTERIDE AND HYDRIDE IN MgO CRYSTALS
}

\author{
M. A. MONGE,* R. PAREJA,* R. GONZÁLEZ*, Y. CHEN** \\ *Departamento de Física, Universidad Carlos III de Madrid, C/Butarque 15, 28911 Leganés (Spain) \\ **U.S. Department of Energy, ER 131, Division of Materials Sciences, Office of Basic Energy Sciences, \\ Washington, D.C., 207874-1290(USA)
}

(Received August 26, 1996)

\begin{abstract}
Low-temperature positron lifetime and Doppler broadening measurements were made in $\mathrm{MgO}$ crystals containing $\mathrm{D}^{-}$or $\mathrm{H}$ ions in order to investigate the temperature dependence of the positron trapping by $\mathrm{D}^{-}$and $\mathrm{H}^{-}$ions and elucidate the possible formation of PsD (PsH) states. Positrons are trapped at $\mathrm{D}^{-}$and $\mathrm{H}^{-}$ions once the oxygen vacancies, which are more effective positron traps, are eliminated by annealing the crystals at high temperatures in a reducing atmosphere. From the temperature dependence of the annihilation parameters the positron trapping coefficients for $\mathrm{D}^{-}$and $\mathrm{H}^{-}$ centers were shown to increase with temperature between $100-300 \mathrm{~K}$. The lifetime of the PsD (PsH) state is $(650 \pm 30)$ ps and temperature independent. The dissociation rate of the PsD (PsH) state into D $(\mathrm{H})$ and $\mathrm{Ps}$ is also temperature independent. No isotopic effect was observed.
\end{abstract}

Theoretical and experimental investigations of the formation of simple positronium compounds are necessary in order to use both positron and positronium (Ps) as chemical probes. In the past positron-anion bound sates $\left[e^{+} X^{-}\right)$or positronium compounds of the type PsX, have been theoretically investigated. ${ }^{1,2}$ Calculations demonstrate that certain light PsX molecules are stable and their annihilation characteristics can be predicted. However, the detection of these Ps-compounds is difficult and uncertain.

Although positron lifetime spectra from liquid solutions show lifetime components that may, in principle, be attributed to the formation of $e^{+}$- or Ps-compounds, it is very difficult to identify unambiguously which $e^{+}$- or Ps-complexes are responsible for these lifetime components. In addition, it is difficult to resolve the complex spectra into three or more components. Thus the analyses can provide only limited quantitative information.

PsH has been observed when a thermalized positron is trapped by an $\mathrm{H}^{-}$ion (a proton with two electrons substituting for an indigenous $\mathrm{O}^{2-}$ ion) in $\mathrm{MgO}$ crystals, ${ }^{3}$ and as a result of collisions between positrons and $\mathrm{CH}_{4}$ molecules. ${ }^{4}$ Thermochemically reduced hydrogen doped $\mathrm{MgO}$ crystals are ideal to investigate $\mathrm{PsH}$ because (1) the positron annihilation characteristics in these crystals are known, (2) the positron lifetime spectrum is simple, and (3) the concentration of $\mathrm{H}^{-}$ions and other lattice defects that 
trap positrons can be monitored by optical absorption measurements. Ps is observed in $\mathrm{MgO}$ containing $\mathrm{H}^{-}$ions only after stronger positron traps such as neutral anion vacancies ( $F$ centers) are annealed out.

In a previous paper, ${ }^{3}$ we have determined the lifetime of the $\mathrm{PsH}$ in $\mathrm{MgO}$, and its dissociation rate into Ps and $\mathrm{H}$. In this work, the temperature effect on the formation of both positronium hydride ( $\mathrm{PsH}$ ) and deuteride (PsD), and on their annihilation parameters is studied. In addition, the possibility of an isotopic effect on the annihilation characteristics is investigated.

\section{Experimental}

The MgO crystals used were grown by the arc fusion method at he Oak Ridge National Laboratory using high purity-grade $\mathrm{MgO}$ powder from the Kanto Chemical Company, Tokyo (Japan). Large concentrations of hydrogen and deuterium in the crystals were obtained by presoaking $\mathrm{MgO}$ powder in $\mathrm{H}_{2} \mathrm{O}$ and $\mathrm{D}_{2} \mathrm{O}$, respectively. In order to produce $\mathrm{H}^{-}$and $\mathrm{D}^{-}$ions, the crystals were subjected to severe thermochemical reduction (TCR) at high temperature $(-2400 \mathrm{~K})$ and under high pressure $\mathrm{Mg}$ or $\mathrm{Ca}$ vapor $(\sim 7 \mathrm{~atm})$ in a tantalum chamber, followed by rapid cooling. 5,6 This TCR treatment produces a high concentration of $\mathrm{F}$ centers. A proton (deuteron) can be trapped at one of these vacancies resulting in an $\mathrm{H}^{-}\left(\mathrm{D}^{-}\right)$ion. $\mathrm{F}$ centers produce an optical absorption band at $250 \mathrm{~nm}$, while $\mathrm{H}^{-}$ions can be monitored by local vibrational modes at 1053,1032 and $1024 \mathrm{~cm}^{-1}$. The absorption bands for $\mathrm{D}^{-}$lie in the reststrahlen and can not be observed. The concentration of $F$ centers and $\mathrm{H}^{-}\left(\mathrm{D}^{-}\right)$ions are determined from optical absorption measurements.

Deuterium doped crystals always contain hydrogen. The ratio between the $\mathrm{H}^{-}$ion and the $\mathrm{D}^{-}$ion concentrations was estimated to be $1: 4$. In as-grown crystals, the same ratio is observed between the intensity of the $2445 \mathrm{~cm}^{-1}$ and the $3296 \mathrm{~cm}^{-1}$ bands associated with $V_{\mathrm{OD}}$ and $V_{\mathrm{OH}}$ centers, respectively. A $V_{\mathrm{OD}}$ center has the following linear configuration $\mathrm{OD}^{-}-[\mathrm{Mg}$ vacancy $]-\mathrm{O}^{2-}$. Replacing deuterium for hdrogen gives the $V_{\text {oH }}$.

Positron lifetime measurements were performed in the temperature range $100-300 \mathrm{~K}$, with the samples inside a liquid- $\mathrm{N}_{2}$ flow cryostat. The spectra were obtained with a 235 ps resolution (FWHM) spectrometer. The lifetime spectra were analyzed by means of the POSITRONFIT program. Doppler-broadening experiments were performed over a temperature range of $10-300 \mathrm{~K}$ in an optical He-closed cycle cryostat. The annihilation radiation was recorded with a $\mathrm{Ge}$ detector with a resolution of $1.62 \mathrm{keV}$ at $1.33 \mathrm{MeV}$ line of ${ }^{60} \mathrm{Co}$. The Doppler broadening of the annihilation peak was characterized by the lineshape parameter $S$ describing the fraction of annihilation events in an energy window of $(511.0 \pm 0.8) \mathrm{keV} . \mathrm{A}^{22} \mathrm{Na}$ positron source sandwiched between a pair of samples was used. 


\section{Results and discussion}

\section{Doppler broadening measurements}

The $S$ parameter for as-grown and thermochemicaliy reduced samples, intentionally doped with $\mathrm{H}$ or $\mathrm{D}$, shows a weak temperature dependence. However, as the $\mathrm{F}$ center content in the thermochemically reduced samples is lowered by successive reducing

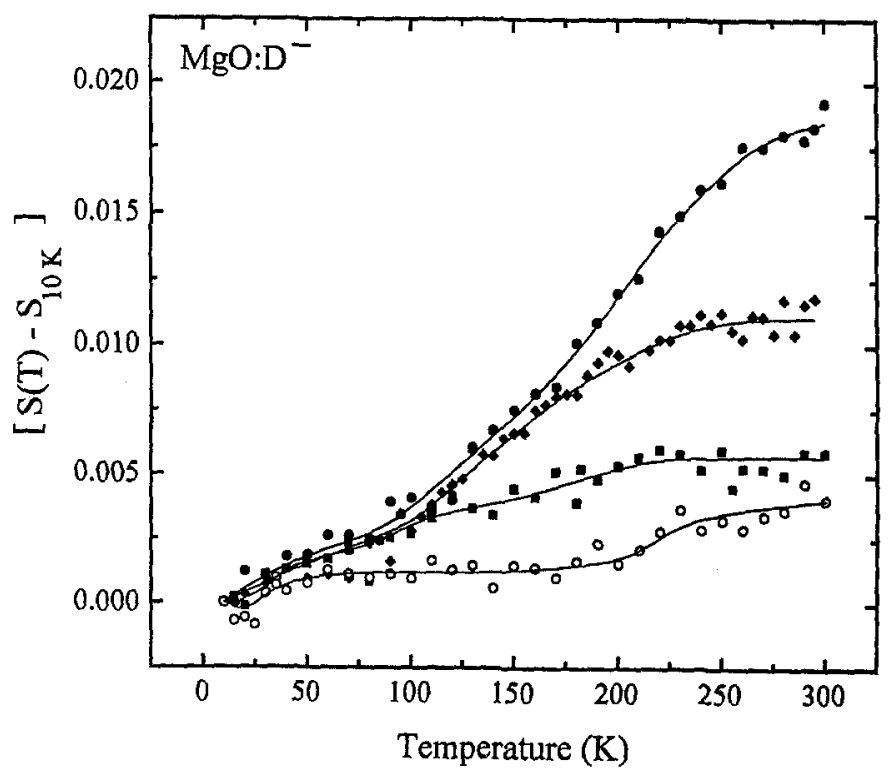

Fig. 1. Difference $\left[S(T)-S_{10 \mathrm{~K}}\right]$ versus temperature for a pair of $\mathrm{MgO}: \mathrm{D}^{-}$samples; $\mathrm{As}-\mathrm{TCR}$ with $[\mathrm{F}]=$ $=1.0 \cdot 10^{-6} \mathrm{at}^{-1}$, after annealing at $1380 \mathrm{~K}$ for $30 \mathrm{~min},[\mathrm{~F}]=1.4 \cdot 10^{-8} \mathrm{at}^{-1}, \bullet$ after annealing at $1440 \mathrm{~K}$ for $10 \mathrm{~min}$, without $\mathrm{F}$ centers, and $O$ after annealing at $1870 \mathrm{~K}$ for $45 \mathrm{~min}$ in an oxydizing atmosphere, without $\mathrm{F}, \mathrm{D}^{-}$and $\mathrm{H}^{-}$centers. The $\mathrm{D}^{-}$and $\mathrm{H}^{-}$concentrations for $\boldsymbol{\square}, \bullet$ and $\rightarrow$ were $7.4 \cdot 10^{-6}$ and $1.9 \cdot 10^{-6}$ at $^{-1}$, respectively

treatments at $1380 \mathrm{~K}$ in a graphite container, this dependence slowly increases. Figure 1 shows the difference $\left[S(T)-S_{10 \mathrm{~K}}\right]$ versus temperature for a pair of thermochemically reduced D-doped $\mathrm{MgO}$ crystals; $S_{10 \mathrm{~K}}$ is the $S$ value measured at $10 \mathrm{~K}$. After annealing out all $\mathrm{H}^{-}$centers in flowing oxygen at $1870 \mathrm{~K}$, the temperature dependence is very weak, and $\left[S(T)-S_{10 \mathrm{~K}}\right]$ shows the same temperature dependence as a pair of as-grown crystals. The same behavior is observed for a pair of thermochemically reduced H-doped samples. 


\section{Positron lifetime measurements}

After TCR the positron lifetime spectra of $\mathrm{MgO}$ crystals doped with $\mathrm{H}$ or $\mathrm{D}$ exhibit two components, but they become three-component spectra when the $\mathrm{F}$ center concentration is lowered by reducing treatments. Figure 2 depicts the mean positron lifetime \langle\rangle as a function of temperature for a pair of D-doped samples. The mean lifetime of the thermochemically reduced $\mathrm{H}$-doped samples shows the same behavior.

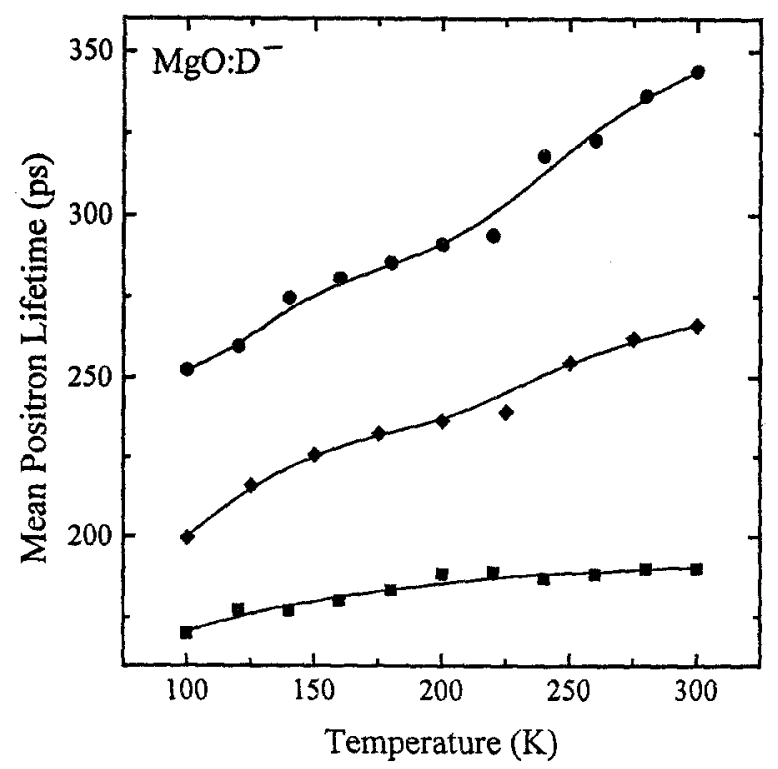

Fig. 2. Mean positron lifetime versus temperature for a pair of $\mathrm{MgO}$ : $\mathrm{D}^{-}$samples; $\mathrm{As}$-TCR with $[\mathrm{F}]=1.0$ $\cdot 10^{-6}$ at $^{-1}$, after annealing at $1380 \mathrm{~K}$ for $30 \mathrm{~min},[\mathrm{~F}]=1.4 \cdot 10^{-8} \mathrm{at}^{-1}$, and $\bullet$ after annealing at $1440 \mathrm{~K}$ for $10 \mathrm{~min}$, without $\mathrm{F}$ centers. The $\mathrm{D}^{-}$and $\mathrm{H}$ concentrations were $7.4 \cdot 10^{-6}$ and $1.9 \cdot 10^{-6} \mathrm{at}^{-1}$, respectively

For thermochemically reduced samples, the lifetime values of the second component, $\tau_{2}$, are essentially temperature independent: $(250 \pm 50) \mathrm{ps}$ and $(350 \pm 30) \mathrm{ps}$ in the $\mathrm{H}-$ and D-doped samples, respectively. For both types of samples the increase of $\langle\tau\rangle$ with temperature is due to an increase in the intensity of the second component $I_{2}$. This second component could be attributed to positron trapping at $F$ centers because the $\tau_{2}$ value gradually increases up to $\sim 520 \mathrm{ps}$ when the concentration of $\mathrm{F}$ centers is lowered by reducing treatments at $1380 \mathrm{~K}$. However, we have found that the $\tau_{2}$ value for thermochemically reduced crystals changes with the $\mathrm{H}$ or D content and the F center concentration. The higher the $\mathrm{H}$ or D content and $\mathrm{F}$ concentration, the higher the $\tau_{2}$ value. This suggests that the positron traps responsible for this second component are 
not only $\mathrm{F}$ centers but also some complex defects formed by association of anion vacancies and protons or deuterons.

The reducing treatments produce dramatic changes in the lifetime spectra. When the $F$ center concentration decreases to about $10^{15} \mathrm{~cm}^{-3}$ and the $\mathrm{H}^{-}$or $\mathrm{D}^{-}$concentration is $10^{18} \mathrm{~cm}^{-3}$, the spectra becomes three-component. The lifetime values of the second and third components, $\tau_{2}$ and $\tau_{3}$ are temperature independent although their values gradually

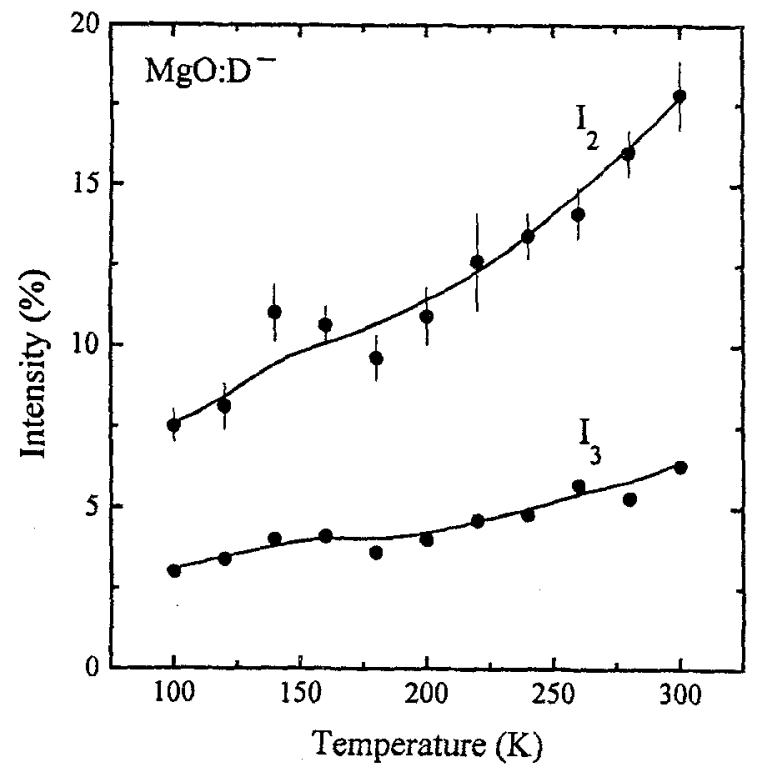

Fig. 3. Intensities $I_{2}$ and $I_{3}$ versus temperature for a pair of $\mathrm{MgO}: \mathrm{D}^{-}$samples, without $\mathrm{F}$ centers, containing $\mathrm{D}^{-}$and $\mathrm{H}^{-}$concentrations of $7.4 \cdot 10^{-6}$ and $1.9 \cdot 10^{-6} \mathrm{at}^{-1}$, respectively

increase as the $F$ center concentration decreases. After annealing out all the $F$ centers, the $\tau_{2}$ value is $(510 \pm 30) \mathrm{ps}$ and $(500 \pm 30)$ ps for the $H$ - and D-doped samples, respectively. The lifetime $\tau_{3}$ value is $(2.2 \pm 0.2) \mathrm{ns}$ for both types of samples. In all cases, the intensities $I_{2}$ and $I_{3}$ increase with temperature as shown in Fig. 3.

The above results indicate that the temperature dependence of the annihilation parametes $S$ and \langle\rangle$\rangle$ is due to an increase of the positron trapping at the defects responsible for the second and third components. In thermochemically reduced H-doped $\mathrm{MgO}$ crystals, it has been demonstrated that $\mathrm{H}^{-}$ions are positron traps forming PsH states. The second component is attributed to the annihilation of these states, and the third component to annihilation of ortho-Ps states created by the PsH dissociation into Ps and $\mathrm{H}$. Since no differences between the results for the $\mathrm{H}$ - and D-doped samples are found, it can be concluded that $\mathrm{D}^{-}$ions trap thermalized positrons forming PSD states. 


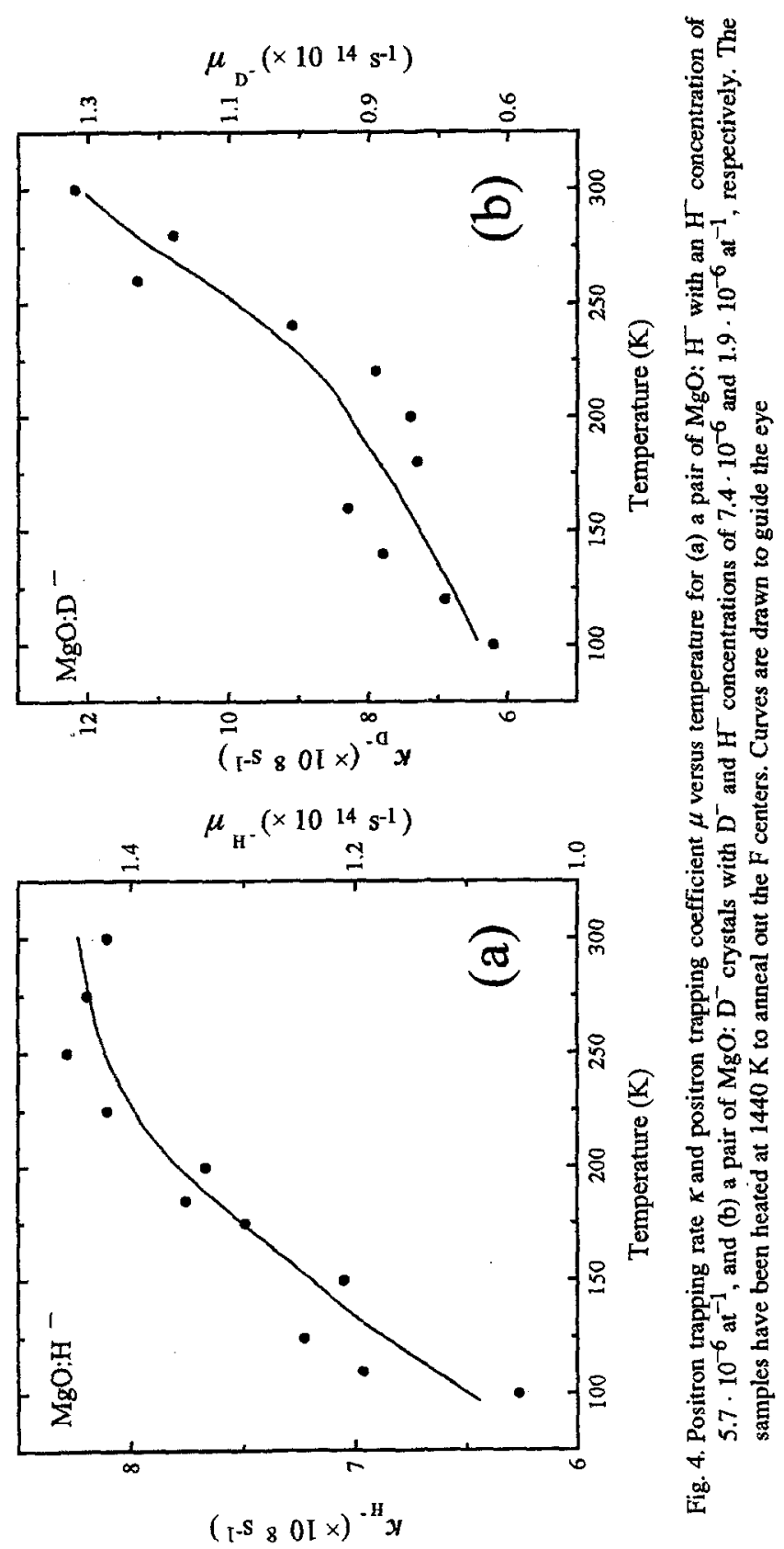


Using the equation of the positron decay model for $\mathrm{MgO}$ containing $\mathrm{H}^{-}$ions and no F centers ${ }^{3}$ (see Appendix), we have determined (1) the dissociation rates for the PsH (PsD) states, (2) their lifetime $\tau_{\mathrm{PSH}}\left(\tau_{\mathrm{PSD}}\right)$ and (3) the trapping rates, $\kappa_{\mathrm{H}-}\left(\kappa_{\mathrm{D}}\right)$, at $\mathrm{H}^{-}$and $\mathrm{D}^{-}$versus temperature. For the temperature range $100-300 \mathrm{~K}$, the dissociation rates and the lifetime for PsH or PsD are $(1.42 \pm 0.12) \cdot 10^{8} \mathrm{~s}^{-1}$ and $(650 \pm 30) \mathrm{ps,}$, respectively. Nevertheless, the positron trapping coefficient for $\mathrm{H}^{-}$or $\mathrm{D}^{-}$increases with temperature as shown in Fig. 4. Assuming $\kappa_{\mathrm{H}^{-}}=\mu_{\mathrm{H}^{-}} C_{\mathrm{H}^{-}}$(or $\kappa_{\mathrm{D}^{-}}=\mu_{\mathrm{D}^{-}} C_{\mathrm{D}-}$ ) the positron trapping coefficient for $\mathrm{H}^{-}$or $\mathrm{D}^{-}$ions can be calculated using the $\mathrm{H}^{-}\left(\mathrm{D}^{-}\right)$concentration $C_{\mathrm{H}}\left(C_{\mathrm{D}}\right)$ obtained from optical absorption measurements. The trapping coefficients are also shown in Fig. 4. Although the PsH lifetime is about $12 \%$ higher than the value previously reported, ${ }^{3}$ the dissociation rate and trapping coefficient agree with those given in Reference 3.

The lifetime value of $(650 \pm 30)$ ps is about 1.5 times higher than the more recent values predicted for $\mathrm{PsH}$ in vacuum. ${ }^{7,8}$ We believe that the lifetime values predicted for $\mathrm{PsH}$ in vacuum cannot be extrapolated to PsH in ionic crystals because in the latter the $\mathrm{PsH}$ molecule must be polarized by the lattice; the polarization of the PsH molecule enhances its lifetime.

Finally, it should be noted that the slight increase of the positron trapping coefficient, $\mu_{\mathrm{H}-}\left(\mu_{\mathrm{D}-}\right)$, with temperature is in agreement with the temperature dependence theoretically predicted for positively-charged vacancies in wide-gap crystals, ${ }^{9} \mathrm{H}^{-}\left(\mathrm{D}^{-}\right)$ ions in $\mathrm{MgO}$ are positively charged centers relative to the lattice.

\section{Conclusion}

We conclude that in $\mathrm{MgO}$, PsD states are formed by trapping of thermalized positrons at $\mathrm{D}^{-}$ions. The lifetime of the $\mathrm{PsH}$ or PsD molecule, and their dissociation rate appear to be temperature independent and indistinguishable. The temperature dependence of both the $S$ parameter and the mean positron lifetime is consistent with an increase of the positron trapping coefficient for $\mathrm{H}^{-}\left(\mathrm{D}^{-}\right)$ions with temperature, that is, with an increase of the PsH (PsD) formation with temperature.

\section{References}

1. V. I. GOLDANSKII, At. Energy Rev., 6 (1968) 3.

2. D. M. SCHRADER, Materials Sci. Forum, 175-178 (1995) 77.

3. R. PAREJA, R. M. DE LA CRUZ, M. A. PEDROSA, R. GONZÁlEZ, Phys. Rev., B41 (1990) 6220.

4. D. M. SCHRADER, F. M. JACOBSEN, N. P. FRANDSEN, U. MIKKELSEN, Phys. Rev. Lett., 69 (1992) 57.

5. R. GONZÁLEZ, Y. CHEN, M. MOSTOLLER, Phys. Rev., B24 (1981) 6862.

6. Y. CHEN, R. GONZÁLEZ, O. E. SCHOW, G. P. SUMMERS, Phys. Rev., B27 (1983) 1276.

7. D. C. CLARY, J. Phys., B9 (1976) 3115.

8. Y. K. HO, Phys. Rev., A34 (1986) 609.

9. M. J. PUSKA, C. CORBEL, R. M. NIEMINEN, Phys. Rev., B41 (1990) 9980. 